\title{
Eficácia do controle de biofilme dental em pacientes portadores de transtorno psiquiátrico
}

\author{
Biofilm dental control effectiveness in patients with psychiatric disorder \\ Eficacia del control de biofilm dental en pacientes portadores \\ de trastorno psiquiátrico
}

\author{
Karine TAKAHASHI \\ Ariane Santana NUNES \\ Eberti Cristovão SANTOS \\ Luis Henrique Pereira dos SANTOS \\ Heitor Ceolin ARAUJO \\ Rosana Leal do PRADO
}

Universidade do Oeste Paulista, UNOESTE 19050.920 Presidente Prudente-SP, Brasil

\begin{abstract}
Resumo
Introdução: A desorganização da placa bacteriana dentária através da higienização mecânica é o meio mais eficaz para evitar processo inflamatório bucal. A negligência da remoção mecânica do biofilme acarreta gengivite com possível evolução a periodontite. A Doença Periodontal é a condição bucal mais preocupante entre os pacientes com distúrbios mentais, apesar de prazeroso cuidar do familiar psicopatológico há uma sobrecarga aos cuidadores, assim as alterações psiquiátricas devem ser identificadas o quanto antes visando manutenção da higienização pessoal e bucal. Objetivo: Esta pesquisa teve como objetivo avaliar as condições bucais periodontais e de higiene oral de pacientes frequentadores de instituição psiquiátrica tanto na forma de internação (hospital Especialidade - HE) quanto na presença diária (Hospital Dia - HD), correlacionando as condições bucais encontradas e grau de higiene bucal. Material e Método: Para tanto, avaliou-se pacientes do hospital psiquiátrico Allan Kardec localizado na região de Presidente Prudente - SP. Grau de higiene oral deu-se pela coloração da placa por pastilha evidenciadora e aplicação do Índice Higiene Oral Simplificado (IHOS). A seguir, realizou-se avaliação das condições periodontais pelo Índice Periodontal Comunitário. Resultados: Uma amostra de 47 pacientes participou do estudo, sendo 19 em sistema de HD e 28 do HE, tanto os em sistema HD e HE, na variável IHOS, observou-se mais prevalente score 3, sendo 42,11\% para HD e 35,71\% para HE, na variável Profundidade de Sondagem mais prevalente foi de 4 a $5 \mathrm{~mm}$ tanto para HD quanto para HE sendo 35,71\%, e 47,37\% respectivamente. Conclusão: não foi verificada diferença estatisticamente significante entre os grupos avaliados $(p>0,005)$.

Descritores: Doenças Periodontais; Transtornos Mentais; Biofilmes; Placa Dentária.
\end{abstract}

\begin{abstract}
Introduction: Disorganization of dental plaque through mechanical hygiene is the most effective way to avoid an inflammatory process of the mouth. The negligence of the mechanical removal of the biofilm causes gingivitis with possible evolution to periodontitis. Periodontal disease is the most worrisome oral condition among patients with mental disorders, although it is a pleasure to take care of the psychopathological relative to the caregivers, so the psychiatric changes must be identified as soon as possible in order to maintain personal and oral hygiene. Objective: This study aimed to evaluate periodontal and oral hygiene conditions of patients attending a psychiatric institution, both in the form of hospitalization (Special - HE hospital) and in daily presence (Day - HD Hospital), correlating the oral conditions found Degree of oral hygiene. Material and Method: Allan Kardec psychiatric hospital located in the region of Presidente Prudente - SP was evaluated. Degree of oral hygiene was obtained by the staining of the plaque by evidence tablet and application of the Simplified Oral Hygiene Index (IHOS), after which periodontal conditions were evaluated by the Community Periodontal Index. Results: A sample of 47 patients participated in the study, being 19 in the HD system and 28 in the HE, both in the HD and HE systems, in the IHOS variable, a more prevalent score was observed 3 , 42.11\% for HD and $35.71 \%$ for HE, the most prevalent Periodontal Diseases was 4 to $5 \mathrm{~mm}$ for $\mathrm{HD}$ and HE, 35.71\%, and $47.37 \%$, respectively. Conclusion: There was no statistically significant difference between the groups evaluated ( $p>0.005)$. Descriptors: Periodontal Diseases; Mental Disorders; Biofilms; Dental Plaque.
\end{abstract}

\section{Resumen}

Introducción: La desorganización de la placa dental a través de la higienización mecánica es el medio más eficaz para evitar el proceso inflamatorio bucal. La negligencia de la remoción mecánica del biopelícula acarrea la gingivitis con posible evolución la periodontitis. La enfermedad periodontal es la condición bucal más preocupante entre los pacientes con trastornos mentales, a pesar de que el cuidado del familiar psicopatológico tiene una sobrecarga a los cuidadores, así que las alteraciones psiquiátricas deben ser identificadas cuanto antes buscando el mantenimiento de la higienización personal y bucal. Objetivo: Esta investigación tuvo como objetivo evaluar las condiciones bucales periodontales y de higiene oral de pacientes frecuentadores de institución psiquiátrica tanto en la forma de internación (hospital Especialidad - HE) como en la presencia diaria (Hospital Día - HD), correlacionando las condiciones bucales encontradas y grado de higiene bucal. Material y Método: Para ello, se evaluaron pacientes del hospital psiquiátrico Allan Kardec ubicado en la región de Presidente Prudente - SP. El grado de higiene oral se dio por la coloración de la placa por pastilla evidenciadora y aplicación del Índice Higiene Oral Simplificada (IHOS). A continuación, se realizó una evaluación de las condiciones periodontales por el Índice Periodontal Comunitario. Resultados: Una muestra de 47 pacientes participó en el estudio, siendo 19 en el sistema de HD y 28 del HE, tanto en el sistema HD y HE, en la variable IHOS, se observó más prevalente score 3 , siendo $42,11 \%$ para HD y $35,71 \%$ para HE, en la variable Profundidad de Sondeo más prevalente fue de 4 a $5 \mathrm{~mm}$ tanto para HD como para HE siendo 35,71\%, y el 47,37\% respectivamente. Conclusión: no se verificó diferencia estadísticamente significativa entre los grupos evaluados ( $\mathrm{p}>0,005)$.

Descriptores: Enfermidades Periodontales; Transtornos Mentales; Biopelículas; Placa Dental.

\section{INTRODUÇÃO}

A doença periodontal é uma doença inflamatória e infecciosa crônica que envolve o acúmulo de placa bacteriana (biofilme) dentária juntamente com fatores genéticos e ambientais, comprometendo os tecidos de suporte dos dentes $^{1}$.

O biofilme dental é constituído por bactérias, proteínas salivares e células epiteliais descamadas, sendo o principal fator etiológico e iniciador para as doenças cárie e periodontal ${ }^{2-4}$.
Bactérias periodontopatogênicas, Gram negativas, são considerados fatores principais e iniciadoras para se desenvolver uma doença periodontal, porém, autores acreditam numa combinação de diversos fatores para uma extensão e gravidade da doença, incluindo caraterísticas do indivíduo, fatores sociais e comportamentais, fatores sistêmicos, genéticos, microbiologia da placa entre outros riscos, e defendem a busca constante de critérios para avaliar 
a susceptibilidade as doenças periodontais visando assim uma melhor prevenção ${ }^{4,5}$.

Quando negligenciado a atenção ao biofilme dental, este evolui para processos inflamatórios desenvolvendo a doença periodontal. Inicialmente ela se manifesta por um sangramento gengival, edema ou hiperemia (gengivite), se não tratada ela pode evoluir para periodontite ${ }^{2}$.

As primeiras alterações clínicas da periodontite caracterizam-se pela perda de inserção dos tecidos periodontais que suportam e protegem o elemento dental, formando a bolsa gengival. Com a fragilidade do elemento dental, ocorre acumulo de biofilme e destruição de tecidos devido a proliferação de microorganismos patogênicos. A doença periodontal quando agravada causa reabsorção das fibras colágenas do ligamento periodontal, reabsorção óssea na região alveolar, abscessos e perda total do tecido dental ${ }^{2}$.

Em uma gengiva saudável a profundidade da sonda permanece no epitélio juncional, apresentando coloração rosa e não observa hemorragia, tendo como profundidade de sondagem $2,5 \mathrm{~mm}$, quando a sondagem perfura o epitélio juncional, estacionando nas fibras colágenas havendo sangramento, constata-se gengivite, no caso da sondagem perfurar o epitélio juncional provocando sangramento e parando somente em contato com o osso, determina-se periodontite, profundidade de sondagem $7,5 \mathrm{~mm}^{6}$.

Estudos mostram importância do controle do biofilme sendo este presente em toda e qualquer lesão de cárie. Enfocam na importância da prevenção através do meio químico ou mecânico, salientando que o controle mecânico, quando feito corretamente, sendo mais eficaz, pois não provocam alterações do meio bucal, ao contrário dos agentes químicos que podem provocar lesões na mucosa bucal ${ }^{7,8}$.

$\mathrm{O}$ transtorno mental conhecido também por doença mental, transtorno psiquiátrico entre outras nomenclaturas, são condições de anormalidade e sofrimento. Os portadores de transtornos mentais e comportamentais apresentam disfunções cerebrais que, de acordo com o grau de comprometimento intelectual, requerem ou não internação hospitalar (OMS, 1996), entretanto, esses pacientes necessitam de atenção especial, seja por tempo indeterminado ou por um período de sua vida, pois eles apresentam desvios comportamentais da normalidade ${ }^{9,10}$

$\mathrm{O}$ indivíduo que apresenta doença mental necessita de assistência adequada com o intuito de ressocialização do mesmo. O núcleo familiar é responsável pelo apoio físico, emocional, social e psicológico do doente embasados por uma orientação profissional adequada. Durante muitos anos a pessoa doente era afastada da família, pois acreditava-se que este contato atrapalharia as melhoras, porém a partir da reforma psiquiátrica entende-se que todo paciente precisa de um tratamento digno e a participação da família é essencial para sua recuperação ${ }^{10,11}$.

O descredito da importância da saúde bucal e a falta de comprometimento dos serviços públicos levam os cuidadores e ou responsáveis a negligenciar a saúde bucal dos seus dependentes, isto devido a alguns fatores, tais como despreparo do profissional, falta de conhecimento e informações por todos quando relacionado a saúde bucal ${ }^{12}$

Apesar da satisfação de cuidar de um paciente psiquiátrico os parentes relatam uma sobrecarga e além disso acabam que colocando suas necessidades e desejos em segundo plano, pois reorganizam suas vidas em prol do paciente, com isso faz-se necessário, ainda, a existência de clinicas de repouso e instituições de internação ${ }^{11-13}$.

Destaca-se ainda sobre esses pacientes, na sua grande maioria o uso de medicamentos psicoativos, tendo eles como características a xerostomia, ou seja, diminuição do fluxo salivar, esta que possui fundamental importância para a homeostasia do meio bucal, facilitando a instalação de doenças na mucosa oral ${ }^{14}$.
Chama a atenção aos periodontistas que os fatores psicossociais, tais como angustia, conflitos, depressão, ansiedade podem estar relacionado com o aumento da severidade e comprometimento dos tecidos dentais, em especial, pesquisas apontam o estresse como risco a doença periodontal, sobretudo pelo fato do aumento da produção de corticóides promovendo efeitos deletérios aos tecidos periodontais e diminuição dos linfócitos. E a progressão da DP é agravada quando associados a outros fatores, como tabagismo e principalmente a pobre higiene bucal ${ }^{4,15,16}$.

Atualmente, associa-se doença periodontal e alterações sistêmicas, sendo relatado que as doenças orais desempenham importante papel na etiopatogenia de diversas doenças, entre elas, doença cardíacas coronárias, AVE, endocardite bacteriana, diabetes mellitus e infecções respiratórias ${ }^{16,17}$.

A doença periodontal é a condição bucal mais preocupante entre os pacientes com distúrbios mentais e comportamentais, sendo essa prevalência justificada pelo déficit motor e intelectual, dificultando a higienização bucal adequada para remoção da placa bacteriana ${ }^{14,18}$.

As alterações psiquiátricas devem ser identificadas precocemente, objetivando uma melhor perspectiva de manutenção da higienização pessoal, assim como a bucal. Os odontólogos devem propor intervenção odontológica a esse grupo de pacientes, tendo como primeiro passo a identificação das condições bucais, desde higienização oral a doenças periodontais, além de enfocar aos cuidadores a importância da higienização mecânica para evitar complicações futuras.

Esta pesquisa teve como objetivo avaliar as condições bucais periodontais e de higiene oral de pacientes frequentadores de instituição psiquiátrica tanto na forma de internação quanto na forma de presença diária, correlacionando as condições bucais encontradas e grau de higiene bucal.

\section{MATERIAL E MÉTODO}

Todos os procedimentos aqui descritos passaram previamente pela aprovação do Comitê de Ética da Universidade do Oeste Paulista com parecer final sob o protocolo $\mathrm{n}^{\mathrm{o}} 2527$. Devido à dificuldade de sanidade mental o termo de consentimento livre e esclarecido foi assinado pelo responsável da instituição.

Os pacientes participantes da pesquisa tinham como exigência ser atendidos pelo hospital psiquiátrico Hospital Allan Kardec, localizado na cidade de Presidente Prudente SP, tendo como critério de inclusão a aceitação passiva da avalição, levando em consideração seu bem estar socioemocional do dia da coleta de dados.

Previamente as fichas clínicas individuais foram preenchidas pelo anotador com o propósito de identificação do paciente.

Após o preenchimento da ficha clínica foram feitas sondagens periodontais utilizando-se espelho bucal plano, espátula de madeira e a sonda OMS (sonda utilizada para aferição do Índice Periodontal Comunitário - IPC) para levantamentos epidemiológicos, sob luz natural, com ambos sentados, examinador e pessoa examinada. Preferencialmente, o local para realização dos exames era bem iluminado e ventilado e próximo a uma fonte de água.

A sonda IPC apresenta características como esfera de $0,5 \mathrm{~mm}$ na ponta e área anelada em preto, situada entre 3,5 $\mathrm{mm}$ e $5,5 \mathrm{~mm}$ da ponta. Outras duas marcas na sonda permitem identificar distâncias de $8,5 \mathrm{~mm}$ e $11,5 \mathrm{~mm}$ da ponta do instrumento (Figura 1), em que será verificada profundidade de sulco e permite avaliar a condição periodontal quanto a higidez, sangramento e presença de cálculo ou bolsa.

Utilizando-se o índice periodontal comunitário (IPC) 
avaliou-se a condição periodontal quanto à higidez, sangramento e presença de cálculo ou bolsa.

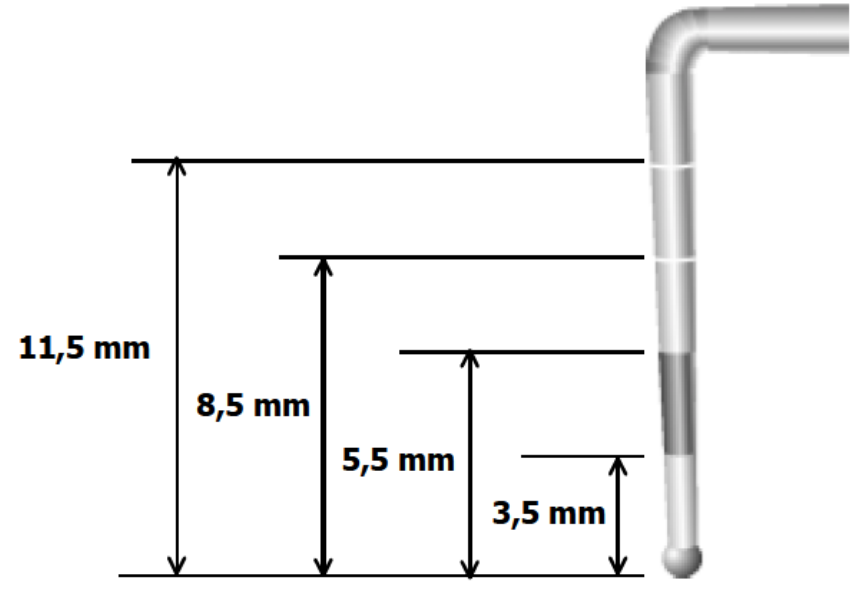

Figura 1: Sonda IPC, ilustrando as marcações com as distâncias, em milímetros, à ponta da sonda (Fonte: Brasil. Ministério da Saúde ${ }^{18}$ ).

Para se iniciar os exames as bocas foram divididas, virtualmente, em sextantes definidos pelos dentes: 18-14, 1323, 24-28, 38-34, 33-43 e 44-48 (Figura 2). A presença de dois ou mais dentes sem indicação de exodontia (comprometimento de furca, mobilidade etc.), foi prérequisito ao exame do sextante. Sem isso, o sextante era cancelado (por exemplo: quando havia um único dente presente). Como dentes índices para cada sextante determinou-se que para pacientes até 19 anos seriam considerados os dentes $16,11,26,36,31$ e 46 . Indivíduos com 20 anos ou mais, os dentes considerados foram 17, 16, $11,26,27,37,36,31,46$ e 47.

Quando nenhum dos elementos dentais estava presente, todos os dentes remanescentes do sextante eram examinados, não se levando em conta a superfície distal dos terceiros molares.

Nos exames, pelo menos 6 pontos foram examinados em cada um dos 10 dentes-índices, nas superfícies vestibular e lingual, abrangendo as regiões mesial, média e distal. Os procedimentos de exame foram iniciados pela área distovestibular, passando-se para a área média e daí para a área mesiovestibular. Após, inspecionaram-se as áreas linguais, indo de distal para mesial. A sonda foi introduzida levemente no sulco gengival ou na bolsa periodontal, ligeiramente inclinada em relação ao longo eixo do dente, seguindo a configuração anatômica da superfície radicular. Movimentos de vai-e-vem vertical, de pequena amplitude, foram realizados. A força na sondagem foi inferior a 20 gramas (verificada pelo seguinte teste prático: colocou-se a ponta da sonda sob a unha do polegar e pressionou-se até obter ligeira isquemia).

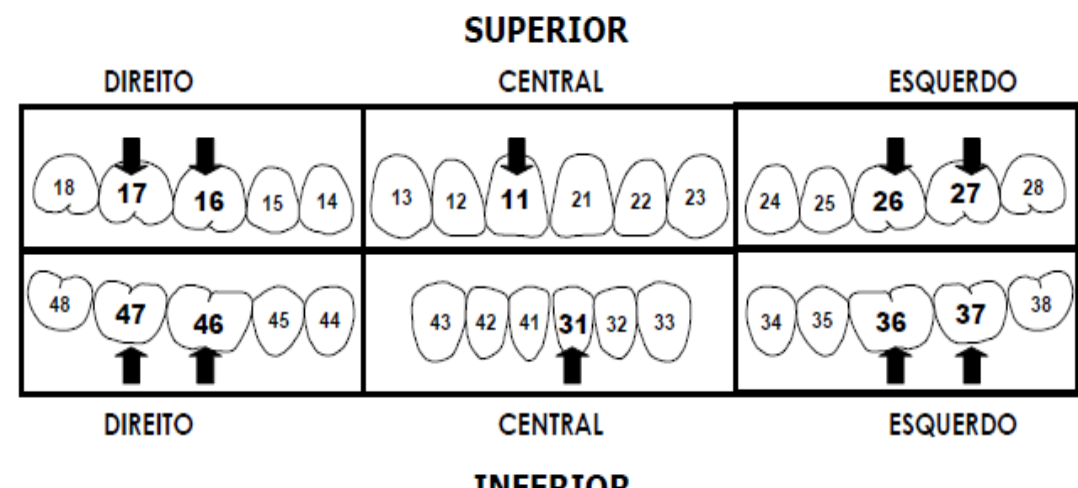

Figura 2: Divisão da arcada em sextantes e destaque dos dentes índices para IPC (Fonte: Brasil. Ministério da Saúde ${ }^{18}$ ).

Com relação aos registros, é importante considerar:

a) Embora 10 dentes tenham examinados, apenas 6 anotações foram feitas: uma por sextante, relativa à pior situação encontrada;

b) quando não houve no sextante pelo menos dois dentes remanescentes e não indicados para extração, cancelou-se o sextante registrando um "X".

No que diz respeito aos códigos, foram os seguintes os códigos utilizados no IPC (Figura 3):
0 - sextante hígido;

1 - sextante com sangramento (observado diretamente ou com espelho, após sondagem);

2 - cálculo (qualquer quantidade, mas com toda a área preta da sonda visível);

3 - bolsa de $4 \mathrm{~mm}$ a $5 \mathrm{~mm}$ (margem gengival na área preta da sonda);

4 - bolsa de $6 \mathrm{~mm}$ ou mais (área preta da sonda não está visível);

$\mathrm{X}$ - sextante excluído (menos de 2 dentes presentes);

9 - sextante não examinado.

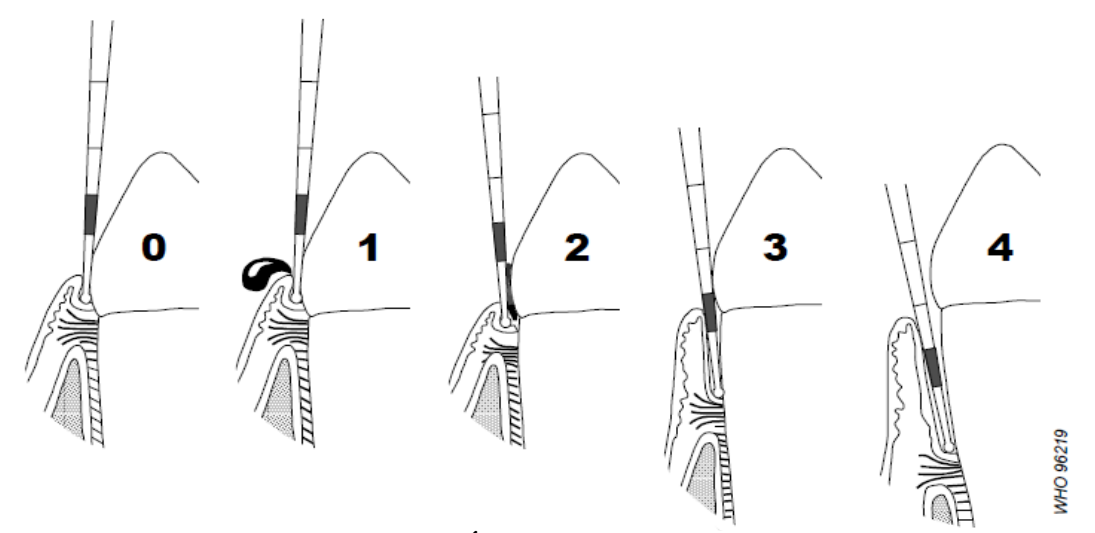

Figura 4: Codificação do Índice Periodontal Comunitário (IPC), ilustrando a posição da sonda para o exame.

Nota: Sabe-se que o tempo de resposta à sondagem da gengiva inflamada é variado. A OMS não define um período de tempo para a observação do sangramento à sondagem. A FSP-USP recomenda um tempo de observação após a sondagem de 10 a 30 segundos, critério utilizado na maioria dos índices com essa categoria de medida e recomendado também pelos pesquisadores que desenvolveram o IPC. (Fonte: Brasil. Ministério da Saúde ${ }^{18}$ ).

Aos pacientes examinados que apresentarem presença de Doença Periodontal, ou por ventura alguma outra patologia na cavidade oral houve orientação sobre o encaminhamento dos mesmos para o setor especifico da Faculdade de Odontologia da UNOESTE para exames diagnósticos completos.

Complementando, foram avaliadas as condições de higiene oral, através do IHOS (índice de higiene oral simplificado), onde foi realizada a coloração da placa por pastilha evidenciadora a base de fucsina básica Eviplac Biodinâmica $^{\mathrm{R}}$ e determinação do Índice de Higiene Oral Simplificado (IHOS) ${ }^{19}$.

Segundo o índice IHOS examinou-se as superfícies dos seguintes dentes: vestibular do primeiro molar superior direito permanente $(16 \mathrm{~V})$; vestibular do incisivo central superior direito permanente $(11 \mathrm{~V})$; vestibular do primeiro molar superior esquerdo permanente $(26 \mathrm{~V})$; lingual do primeiro molar inferior esquerdo permanente (36 L); vestibular do incisivo central inferior esquerdo permanente $(31 \mathrm{~V})$; lingual do primeiro molar inferior direito permanente (46 L) (Figura 4).

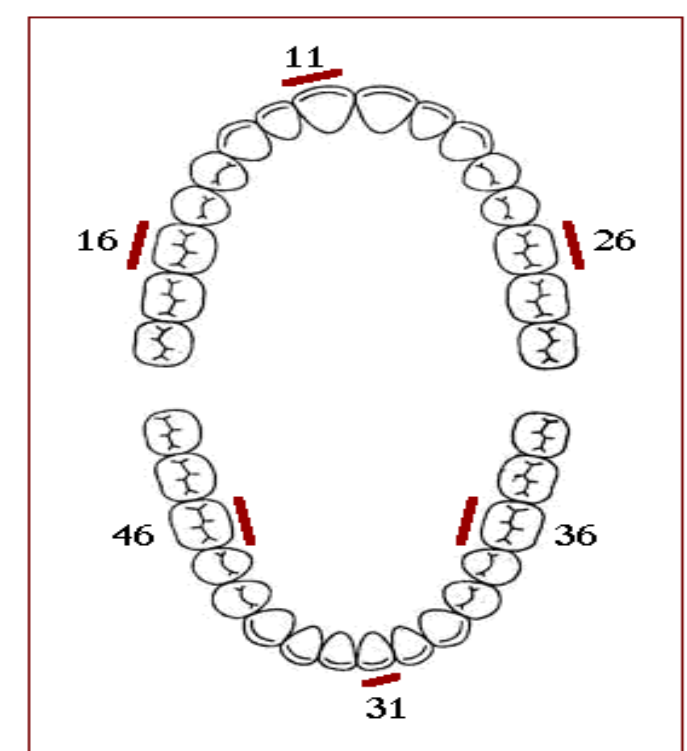

Figura 4: Índice de higiene oral simplificado

(Fonte: http://www.sdpt.net/ID/indicesimplificadohigieneoral.htm)

A escala para índice de placa varia de zero a três, de acordo com os seguintes critérios: Grau zero (0) - ausência de 
placa ou mancha intrínseca; Grau um (1) - presença de placa cobrindo não mais de $1 / 3$ da superfície examinada ou ausência de placa, mas presença de mancha intrínseca; Grau dois (2) - presença de placa cobrindo mais de $1 / 3$, mas não mais de $2 / 3$ da superfície examinada; poderá haver ou não presença de mancha intrínseca; Grau três (3) - presença de placa cobrindo mais de $2 / 3$ da superfície examinada (Figura 5).

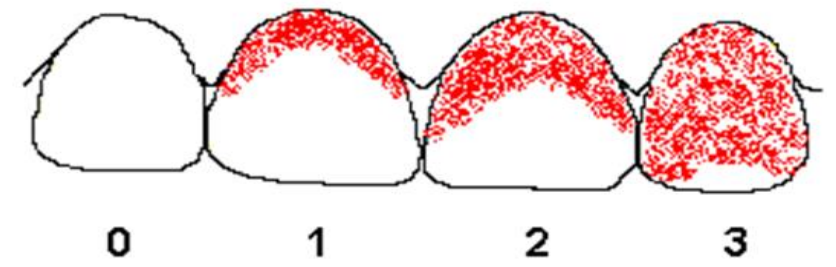

Figura 6: Registro do grau do índice de placa bacteriana (Fonte: http://gabocaperuzo.blogspot.com.br/2012/06/indice-de-higiene-oralsimplificado.html).

Os detritos se definem como a matéria suave aderida ao dente, formada por mucina, bactérias assim como restos alimentares.

Após a realização do IHOS os pacientes foram orientados quanto a presença de placa e a forma ideal de remoção de biofilme bacteriano. Além disso, comprovou-se a efetividade da remoção do biofilme bacteriano através da higienização mecânica.

Os dados obtidos foram anotados em planilha do Microsoft Office Excel ${ }^{\mathrm{R}}$ para aplicação dos testes estatísticos. Os dados foram analisados aplicando-se o teste exato de Fisher, ao nível de significância de 5\%. As análises foram realizadas com o auxílio do software $\mathrm{R}^{1}$, Vienna, Austria ${ }^{20}$.

\section{RESULTADOS}

Uma amostra de 47 pacientes, todos do hospital Psiquiatrico Allan Kardec, participaram do estudo, sendo 19 em sistema de Hospital Dia (HD) e 28 em sistema de Hospital Especialidade (HE), após aplicação dos testes e coletados os dados quanto a variável IHOS, avaliando-se os pacientes em sistema de $\mathrm{HD}$, observou-se como mais prevalente os pacientes com biofilme em mais de $2 / 3$ da superfície dentária, sendo $42,11 \%$, seguido dos pacientes com até $2 / 3$ da superfície e dos que apresentaram os sextantes excluídos, sendo $21,05 \%$ e $15,79 \%$ com presença de biofilme em até $1 / 3$ da superfície dentária, (Tabela 1).

Quando se examinou os pacientes em sistema de HE pode-se constatar que a maioria apresentava biofilme em mais de $2 / 3$ da superfície dentária, sendo $35,71 \%$, seguido pelos os que apresentaram presença de biofilme em até $1 / 3$ da superfície dentária e os com sextante excluídos, respectivamente com os valores $25 \%$ e $17,86 \%$. Foi observado presença de biofilme até $2 / 3$ do dente em 14,29\% da população avaliada, e apenas 7,14\% apresentaram ausência de biofilme sobre a superfície dental (Tabela 1).

Tabela 1. Comparativo do Índice de Higiene Oral Simplificado (IHOS) entre pacientes Frequentadores do Hospital Dia (HD) e Hospital Especialidade (HE), Presidente Prudente. 2016

\begin{tabular}{c|ccc}
\hline IHOS & HD & HE & Total \\
\hline $\mathbf{0}$ & 0 & 2 & 47 \\
& $(0,00 \%)$ & $(7,14 \%)$ & $(100 \%)$ \\
$\mathbf{1}$ & 3 & 7 & 47 \\
& $(15,79 \%)$ & $(25 \%)$ & $(100 \%)$ \\
$\mathbf{2}$ & 4 & 4 & 47 \\
& $(21,05 \%)$ & $(14,29 \%)$ & $(100 \%)$ \\
$\mathbf{3}$ & 8 & 10 & 47 \\
& $(42,11 \%)$ & $(35,71 \%)$ & $(100 \%)$ \\
$\mathbf{X}$ & 4 & 5 & 47 \\
& $(21,05 \%)$ & $(17,86 \%)$ & $(100 \%)$ \\
\hline
\end{tabular}

Quanto à profundidade de sondagem, no sistema HD, a pior condição encontrada foi de 4 a $5 \mathrm{~mm}$ em dez pacientes
$(35,71 \%)$, seguida pelo cálculo subgengival presente em sete pacientes $(25,00 \%)$, depois os sextantes excluídos sendo encontrado em cinco pacientes $17,86 \%$, na sequência aparecem as bolsas de $6 \mathrm{~mm}$ ou mais, sendo visto em quatro pacientes $(14,29 \%)$ e em apenas dois casos $(7,14 \%)$ observou a presença de sangramento imediatamente após a sondagem (Tabela 2).

Tabela 2. Comparativo da Sondagem Periodontal (PS) entre pacientes Frequentadores do Hospital Dia (HD) e Hospital Especialidade (HE).

\begin{tabular}{c|ccc}
\hline PS & HD & HE & Total \\
\hline 0 & 0 & 0 & 47 \\
& $(0,00 \%)$ & $(0,00 \%)$ & $(100 \%)$ \\
1 & 2 & 1 & 47 \\
& $(7,14 \%)$ & $(5,26 \%)$ & $(100 \%)$ \\
2 & 7 & 4 & 47 \\
& $(25,00 \%)$ & $(21,05 \%)$ & $(100 \%)$ \\
3 & 10 & 9 & 47 \\
& $(35,71 \%)$ & $(47,37 \%)$ & $(100 \%)$ \\
4 & 4 & 1 & 47 \\
& $(14,29 \%)$ & $(5,26 \%)$ & $(100 \%)$ \\
$X$ & 5 & 4 & 47 \\
& $(17,86 \%)$ & $(21,05 \%)$ & $(100 \%)$ \\
9 & 0 & 0 & 47 \\
& $(0,00 \%)$ & $(0,00 \%)$ & $(100 \%)$ \\
\hline
\end{tabular}

As análises não mostraram diferenças significativas entre os índices de higiene oral simplificada do HE/HD $(\mathrm{p}=0,7722)$, bem como a sondagem periodontal dos mesmos $(\mathrm{p}=0,8705)$.

\section{DISCUSSÃO}

Os pacientes avaliados neste trabalho pertencem a um Hospital Psiquiátrico sem fins lucrativos com dois sistemas distintos de assistência. Os pacientes que fazem parte do sistema HD são pessoas que ficam na entidade no período das $08 \mathrm{~h} 00$ às $17 \mathrm{~h} 00$, já os pacientes do sistema HE são pessoas que passam por um período de internação não ultrapassando 60 dias de estadia.

Ao realizar o comparativo entre as variáveis profundidade de sondagem (PS) e índice de higiene oral (IHOS) observou que o índice mais elevado tanto para o sistema HD quanto para o HE foram de score 3 para IHOS e score 3 para PS sendo $6(31,58 \%)$ e $6 \quad(21,43 \%)$, respectivamente, estes resultados concordam com os achados em Eltas et al. $(2013)^{21}$, que em seus estudos percebeu ser prevalente a doença periodontal a pacientes psiquiátricos associados a má higienização dentaria. Na sequência verificou-se maior número de pacientes com sextantes excluídos devido ausência de dentes, sendo $4(21,04 \%)$ para HD e $5(17,86 \%)$ para HE, de acordo com Lewis et al. ${ }^{22}$ a doença periodontal está associada a pobre higiene bucal e por consequência a perda do elemento dental se não tratada a doença.

Para os achados de IHOS baixo (score 0 e score 1) percebeu-se apenas sangramento gengival (score 1) e cálculo (score 2) quando relacionado ao exame periodontal, tanto no sistema HD quanto no sistema HE. Segundo Araújo ${ }^{23}$ em seus estudos constatou que a inflamação gengival dá devido ao acumulo de biofilme dental pelo não uso da escova e fio dental, levando a saúde bucal desses indivíduos hospitalizados em situação deterioradora.

Os pacientes avaliados podem ser diagnosticados com doença periodontal crônica e tendo como principal etiologia a presença de biofilme dentário, e autores como Freitas ${ }^{24}$ e Araújo $^{23}$ confirmam que a destruição dos suportes periodontais ou não, está vinculada a susceptibilidade do 
hospedeiro e sua resistência associando a periodontite e esse mecanismo de proteção fisiológica pode degrada-los.

Jamelli et al. ${ }^{14}$ relataram em seus estudos que esse grupo de distúrbios psiquiátricos em sistema de internato tem a doença periodontal como sendo a patologia bucal mais prevalente, porem no presente estudo não notamos diferenças entre os pacientes em sistema de internados ou ambulatorial quando avaliados a variável de Profundidade de sondagem.

Achados da pesquisa mostraram que a relação de sextantes excluídos devido a ausência dos elementos dentais foi $n=4(21,05 \%)$ para $\mathrm{HD}$ e $\mathrm{n}=5(17,86 \%)$ para $\mathrm{HE}$, número relativamente alto. Estudos como o de Lewis et al. ${ }^{22}$ corroboram com os achados deste condizendo que a doença periodontal está associada a pobre higiene bucal e por consequência a perda do elemento dental. Jamelli et al. ${ }^{14}$ também encontrou resultados semelhantes, verificando necessidade de uso de prótese em $42,5 \%$, e perda de inserção periodontal em $28,5 \%$.

Pelas condições de degradação encontradas nos pacientes fica notório que eles chegam a entidade já em condições precárias, estudos como Caetano et al. ${ }^{17} \mathrm{e}$ Neto et al. ${ }^{25}$ citam que em transtornos mentais há uma redução com os cuidados de higiene pessoal e o desinteresse em manter a higiene bucal, achados semelhantes também foram apresentados no trabalho de Haas et al. ${ }^{26}$ que indivíduos com transtornos psíquicos apresentam déficit cognitivo, juntamente com dificuldade motora ao autocuidado de higiene pessoal e bucal, ficando evidente que tais transtornos devem ser diagnosticados precocemente para consequentemente prevenir as consequências da má higienização, cabendo aos cuidadores supervisionarem a higienização dos doentes.

Ao avaliar a medicação da população estudada foi constatado o uso de medicamentos psiquiátricos, tais como: respiridona, sertralina, carbamazepina, ácido valpróico, diazepan, medicamentos estes com grande potencial xerostômico. O presente estudo apoia-se em trabalhos como de Hass et al. ${ }^{26}$ que destaca a rotina de medicamentos psicoativos que levam a uma redução do fluxo salivar e também a dificuldade motora fina levando a ineficácia da higienização bucal, Eltas et al. ${ }^{21}$ corrobora com esses estudos visto que os pacientes psiquiátricos têm maiores risco de desenvolver doença periodontal principalmente devido a medicação, sendo necessário medidas preventivas na boca aliadas ao tratamento sistêmico do paciente.

Como agravante da degradação bucal pode-se observar o alto consumo de cigarros pelos pacientes e tal consumo dáse embasado em estudos como os de Robson e $\mathrm{Gray}^{27}$ posto que o uso de cigarros está relacionado a psicopatologia pois lhes trazem diminuição da ansiedade e dos efeitos psicóticos, definido como uma automedicação e que o consumo de tabaco em pacientes com transtornos mentais graves é mais elevado que na população em geral. Castro ${ }^{28}$ corrobora com estes achados quando afirma que pacientes com alto índice de estresse ou deprimidos, costumeiramente desenvolvem hábitos tabagistas ou intensificam, acarretando severidade a doença periodontal.

Percebeu-se dentro da instituição psiquiátrica visitada certa negligência quanto à questão de higienização bucal levantando o questionamento da razão deste descaso. Como argumentos, percebeu-se duas situações: a primeira caracterizada pela falta de profissionais que atendam dentro da entidade. A segunda, pela não preparação e falta do conhecimento dos cuidadores. Autores como Shapira et al. ${ }^{29}$ afirmam que o treinamento dos cuidadores e noções primarias de prevenção dentro da instituição são de fundamental importância. E que todos os pacientes, independente da saúde mental merecem atendimento dental de qualidade. Para este caso, após abordagem, os pacientes psiquiátricos diagnosticados com necessidade de tratamento odontológico foram encaminhados à clínica da faculdade e palestras educativas aos cuidadores e ações de escovação supervisionada foram sugeridas à direção da instituição psiquiátrica.

A doença mental vista de um aspecto mais amplo caracteriza-se por deixar de ser um problema individual, passando a ser preocupação em nível de saúde pública onde o paciente necessita do acolhimento e convívio familiar para melhores resultados em seu tratamento. Spadini et al. ${ }^{10}$ coloca em seus estudos que, hoje a família é de essencial importância, dando ao paciente um tratamento digno. A reforma psiquiátrica de 1970 teve como objetivo a desinstitucionalização e participação efetiva da família ao tratamento de pessoas com transtorno mentais, saindo daquela visão hospitalocêntrica e com o convívio do paciente mais tempo na comunidade, houve então a criação de programas assistenciais como Núcleo de Atenção Psicossocial (NAPS) e Centro de Atenção Psicossocial (CAPS) ${ }^{30-32}$.

É sabido que a Estratégia Saúde da Família (ESF) é a porta de entrada ao sistema Único de Saúde (SUS) e uma de suas funções é estreitar a relação entre usuário e o sistema. A discussão matricial em saúde mental aplicada ao ESF sugere troca de experiências e ações entre a ESF e CAPS, dando assistência de maneira global efetivando ações de saúde onde possam ser englobadas tanto o paciente quanto sua família ${ }^{33}$, condizendo com essa visão Borba et al. ${ }^{31}$ menciona a importância de inserir a família em grupos de apoio familiares para que saibam conviver com o problema, de maneira que sintam-se capaz e não ao contrário, ajudando de maneira efetiva. Souza et al.$^{32}$ lembra que a Reforma Psiquiátrica não deve ficar trancafiada aos muros dos hospitais psiquiátricos e sim em pleno convívio com a população, promovendo afetividade mutua e tendo a família como suporte.

Sabe-se que nem todo Cirurgião Dentista tem audácia e conhecimento para realizar o tratamento adequado a essa população tão comumente encontrada, sendo que essa especialidade em muitas graduações não encontram-se na grade curricular obrigatória, porém Shapira et al. ${ }^{29}$ desde já sugeria em seu trabalho a necessidade de se treinar o cirurgião dentista no manejo dos indivíduos com transtorno psiquiátrico devido variações comportamentais, que tanto os dentistas quanto os responsáveis pela higienização bucal destes que entendam os problemas desta população podem melhorar a qualidade do tratamento odontológico.

\section{CONCLUSÃO}

Com base nos resultados obtidos, pode-se concluir que apesar de se verificar altos índices de IHOS e PS tanto nos pacientes HD quanto HE, não foi verificada diferença estatisticamente significante entre os grupos avaliados $(\mathrm{p}>0,005)$.

\section{REFERENCIAS}

1. Bastos JA, Vilela EM, Henrique MN, Daibert PC, Fernandes LFMC, Paula DAA et al. Avaliação do conhecimento sobre doença periodontal em uma amostra de nefrologistas e enfermeiros que atuam com doença renal crônica pré-dialítica. J Bras Nefrol. 2011; 33(4):431-5.

2. Alves C, Andion J, Brandão M, Menezes R. Mecanismos patogênicos da doença periodontal associada ao Diabetes Melito. Arq Bras Endocrinol Metab. 2007; 51(7):1050-7.

3. Martins RS, Macêdo JB, Muniz FWMG, Carvalho RS, Moreira MMSM. Composição, princípios ativos e indicações clínicas dos dentifrícios: uma revisão da literatura entre 1989 e 2011. J Health Sci Inst. 2012; 30(3):287-91

4. Greghi SLA. Avaliação quantitativa das citocinas IL-4, IL-8, IL-10 e do TGF-B, presente na saliva de pacientes com periodontite, antes e após a submissão a psicoterapia 
- analise comparativa com pacientes controles [tese] Bauru: Faculdade de Odontologia de Bauru; 2011.

5. Sales LAR, Falabella MEV, Falabella JM, Teixeira HGC, Figueredo CMS. Relação entre doença periodontal e lúpus eritematoso sistêmico. RGO. 2008; 56(2):189-93.

6. Hassell TM, Wolf HF. Manual de Periodontia: fundamentos, diagnósticos, prevenção e tratamento. São Paulo: Artmed; 2008.

7. Lima JEO. Programa preventivo da cárie dentária baseado no controle mecânico da placa bacteriana em crianças, por meio da profilaxia profissional periódica. Resultados após 25 anos de acompanhamento. R Dental Press Ortodon Ortop Facial. 2009; 14(3):44-51.

8. Ferreira RC, Magalhães CS, Rocha ES, Schwambach CW, Moreira AN. Saúde bucal de idosos residentes em instituições de longa permanência de Belo Horizonte, Minas Gerais, Brasil. Cad. Saúde Pública 2009; 25(11):2375-85

9. Gelder M, Mayou R, Cowen P. Tratado de psiquiatria. 4. ed. Rio de Janeiro: Guanabara Koogan; 2006.

10. Carvalho EMC, Araujo RPC. A saude bucal em portadores de transtornos mentais e comportamentais. Pesq Bras Odontoped Clin Integr. 2004; 4(1):65-75.

11. Spadini LS, Souza MCBM. A doença mental sob o olhar de pacientes e familiares. Rev Esc Enferm USP. 2006; 40(1):123-7.

12. Castro AM, Marchesoti MGN, Oliveira FS, Novaes MSP Avaliação do tratamento odontológico de pacientes com necessidades especiais sob anestesia geral. Rev Odontol UNESP. 2010; 39(3):137-42

13. Pereira MAO, Barbieri L, Paula VP, Franco MSP. Saúde mental no Programa de Saúde da Família: conceitos dos agentes comunitários sobre o transtorno mental. Rev Esc Enferm USP. 2007; 41(4):567-72.

14. Jamelli SR, Mendonça MC, Diniz MG, Andrade FBM, Melo JF, Ferreira SR et al. Saúde bucal e percepção sobre $o$ atendimento odontológico em pacientes com transtorno psíquicos moradores de residências terapêuticas. Ciênc saúde coletiva. 2010; 15(1):1795-800.

15. Campos MVC, Scherma AP, Cortelli JR, Franco GCN, Costa FOC, Silva MDP et al. Associação entre estresse, parâmetros microbiológicos e condição clínica periodontal - estudo transversal com alunos da escola de especialistas da aeronáutica. Braz J Periodontol. 2012; 22(3):62-9.

16. Caetano AS, Calil LR, Saraiva PP. Alterações sistêmicas detectadas em pacientes em tratamento periodontal Salusvita. 2013; 32(2):139-48.

17. Kahn S, Mangialardo ES, Garcia CH, Namen FM, Galan Júnior J, Machado WAS. Controle de infecção oral em pacientes internados: uma abordagem direcionada aos médicos intensivistas e cardiologistas. Ciênc Saúde Coletiva. 2010; 15(1):1819-26.

18. Brasil. Ministério da Saúde. Departamento de Atenção Básica. Projeto SB2000: condições de saúde bucal da população brasileira no ano 2000: manual do examinador. Brasília: Ministério da Saúde; 2001.

19. Nascimento S, Scabar LF. Levantamento epidemiológico de cárie, utilizando os índices CPO-D, ceo-de IHOS, nos índios da aldeia Wakri no Estado do Pará. Rev Inst Ciênc Saúde. 2008; 26(2):247-54.

20. R Core Team (2016). R: A language and environment for statistical computing. R Foundation for Statistical Computing, Vienna, Austria.

21. Eltas A, Kartalci S, Eltas CD, Dündar S, Uslu MO. An assessment of periodontal health in patients with schizophrenia and taking antipsychotic medication. Int J Dent Hygiene. 2013; 11(2):78-83.
22. Lewis S, Jagger RG, Treasure E. The oral health of psychiatric in-patients in South Wales. Spec Care Dentist. 2001; 21(5):182-6.

23. Araujo MM. Condição periodontal de indivíduos internados em unidade de terapia intensiva: aspectos clínicos, epidemiológicos e microbiológicos [tese]. Belo Horizonte: Faculdade de Odontologia da Universidade Federal de Minas Gerais (UFMG); 2015.

24. Freitas AR. Condições periodontais e de higiene bucal, qualidade de vida e satisfação com a vida em pacientes obesos diabéticos e não diabéticos submetidos a cirurgia bariátrica. Bauru: Faculdade de Odontologia de Bauru; 2015.

25. Gallucci Neto J, Tamelini MG, Forlenza OV. Diagnostico diferencial das demências. Rev Psiquiatr Clín. 2005; 32(3):119-30.

26. Haas NAT, Alves UM, Rocha VCF. O desafio do diagnóstico oral em pacientes especiais. RFO 2009; 14(3):211-5.

27. Robson D, Gray R. Serious mental illness and physical health problems: A discussion paper. Int J Nurs Stud. 2007; 44(3):457-66.

28. Castro GD. Associação entre eventos de vida, ansiedade e depressão e a doença periodontal [tese]. Porto Alegre: Universidade Federal do Rio Grande do Sul; 2003.

29. Shapira J, Efrat J, Berkey D, Mann J. Dental health profile of a population with mental retardation in Israel. Spec Care Dentist. 1998; 18(4):149-55.

30. Pegoraro RF, Cassimiro TJL, Leão NC. Matriciamento em saúde mental segundo profissionais da estratégia da saúde da família. Psicol estud. 2014; 19(4):621-31.

31. Borba LO, Schwartz E, Kantorski LP. A sobrecarga da família que convive com a realidade do transtorno mental. Acta Paul Enferm. 2008; 21(4):588-94.

32. Souza LGS, Menandro MCS, Couto LLM, Schimith PB, Lima RP. Saúde Mental na Estratégia Saúde da Família: revisão da literatura brasileira. Saúde Soc. 2012; 21(4):1022-34.

33. Tófoli LF, Fortes S. Apoio matricial de saúde mental na atenção primaria no municipio de Sobral, CE: o relato de uma experiencia. Sanare. 2007; 6(2):34-42.

\section{CONFLITO DE INTERESSES}

Os autores declaram não haver conflitos de interesse.

\section{AUTOR PARA CORRESPONDÊNCIA}

\section{Karine Takahash}

karine@unoeste.b

Submetido em 13/02/2018 Aceito em 10/03/2018 